\title{
Prevalence of Acanthosis Nigricans in an urban population in Sri Lanka and its utility to detect metabolic syndrome
}

\author{
Anuradha S Dassanayake1, Anuradhani Kasturiratne1, Madunil A Niriella', Udaya Kalubovila', Shaman Rajindrajith', \\ Arjuna P de Silva', Norihiro Kato ${ }^{2}$, A Rajitha Wickremasinghe ${ }^{1}, \mathrm{H}$ Janaka de Silva ${ }^{{ }^{*}}$
}

\begin{abstract}
Background: Insulin resistance (IR) plays a major role in the pathogenesis of metabolic syndrome. Acanthosis nigricans (AN) is an easily detectable skin condition that is strongly associated with IR. The aims of this study were, firstly, to investigate the prevalence of AN among adults in an urban Sri Lankan community and secondly, to describe its utility to detect metabolic syndrome.

Findings: In a community based investigation, 35-64 year adults who were selected using stratified random sampling, underwent interview, clinical examination, liver ultrasound scanning, and biochemical and serological tests. Metabolic syndrome was diagnosed on revised ATP III criteria for Asian populations. AN was identified by the presence of dark, thick, velvety skin in the neck.

2957 subjects were included in this analysis. The prevalence of AN, metabolic syndrome and type 2 diabetes mellitus were $17.4 \%, 34.8 \%$ and $19.6 \%$, respectively. There was a strong association between AN and metabolic syndrome. The sensitivity, specificity, positive predictive value and negative predictive value of AN to detect metabolic syndrome were $28.2 \%, 89.0 \%, 45.9 \%$ and $79.0 \%$ for males, and $29.2 \%, 88.4 \%, 65.6 \%$ and $62.3 \%$ for females, respectively.
\end{abstract}

Conclusions: AN was common in our study population, and although it did not have a high enough sensitivity to be utilized as a screening test for metabolic syndrome, the presence of AN strongly predicts metabolic syndrome.

\section{Background}

Acanthosis nigricans (AN) is an easily identifiable skin lesion characterized by velvety, brownish-black pigmentation of the skin of the neck and intertriginous surfaces. Typical areas of involvement include the posterior aspect of the neck, axillae, elbows and knees; the neck is involved $93 \%$ to $99 \%$ of the time $[1,2]$. The common occurrence of $\mathrm{AN}$ in the neck is important in a primary care setting because it makes the lesion easily detectable. A quantitative scale of AN has been developed by Burke et al [1]. This scale takes into consideration the severity of $\mathrm{AN}$ in neck and axilla, neck texture, and the presence or absence of AN in knuckles, elbows and knees.

\footnotetext{
* Correspondence: hjdes@sltnet.Ik

${ }^{1}$ Faculty of Medicine, University of Keleniya, Ragama, Sri Lanka

Full list of author information is available at the end of the article
}

A number of studies have shown an association between $\mathrm{AN}$ and insulin resistance [3,4] and the recent increase in the prevalence of AN [5-7] may well reflect increasing trends in obesity and type 2 diabetes worldwide [1]. The prevalence of AN varies from $7 \%$ in unselected populations to $74 \%$ in obese people [5,6]. It has been shown to be a reliable cutaneous marker of insulin resistance in obese Japanese children [8]. The prevalence also varies in different racial groups. For example, African Americans are 25 times more likely to have AN than patients of European descent [2]. A study from the USA reports that the prevalence of AN was 3\% among Caucasians, $19 \%$ in Hispanics and 28\% in American Indians [7]. Although obesity increases the risk of AN, racial differences in the prevalence of AN cannot solely be explained by different rates of obesity. Although a hospital based study from India has reported a prevalence of $\mathrm{AN}$ of $65 \%$ among diabetics and $40 \%$ among 
healthy people attending non-diabetic patients [9], to our knowledge there are no data on community prevalence of AN from the Indian subcontinent.

The diagnosis of metabolic syndrome involves a battery of investigations that poses a challenge to doctors working in poor countries, particularly in a primary care setting. In these situations, where there are many competing demands within the brief patient encounter, a clinical marker to rapidly identify persons at high risk for metabolic syndrome would be very useful. AN may be a suitable clinical marker especially in communities where it is prevalent.

The aims of this study were, firstly to investigate the prevalence of AN in an urban Sri Lankan community, and secondly, to describe its utility to detect metabolic syndrome.

\section{Materials and methods}

This study was part of a community based investigation the Ragama Health Study (RHS), conducted in the Ragama Medical Officer of Health area [10]. This area has characteristics typical of an urban community in Sri Lanka. Participants were a representative sample of 35-64 year old adults selected by stratified random sampling from electoral lists. Ethical approval for the study was obtained from the Ethics Review Committee of the Faculty of Medicine University of Kelaniya. The purpose of the study, the procedures to be carried out with potential hazards and benefits were explained to the individuals prior to obtaining informed written consent. Consenting adults were screened by a structured interview, clinical examination, liver ultrasound ( $8 \mathrm{MHz}$ probe, Toshiba ultrasound diagnostic systems SSA-51 OA, Toshiba Medical Systems Corporation, Otawara-city, Tochigi-prefecture, Japan) and collection of $10 \mathrm{ml}$ venous blood for biochemical tests. Metabolic syndrome was diagnosed on revised ATP III criteria for Asian populations [11]. AN was identified by the presence of dark, thick, velvety, pigmented skin in the neck (Figure 1). The person appearing in the photograph

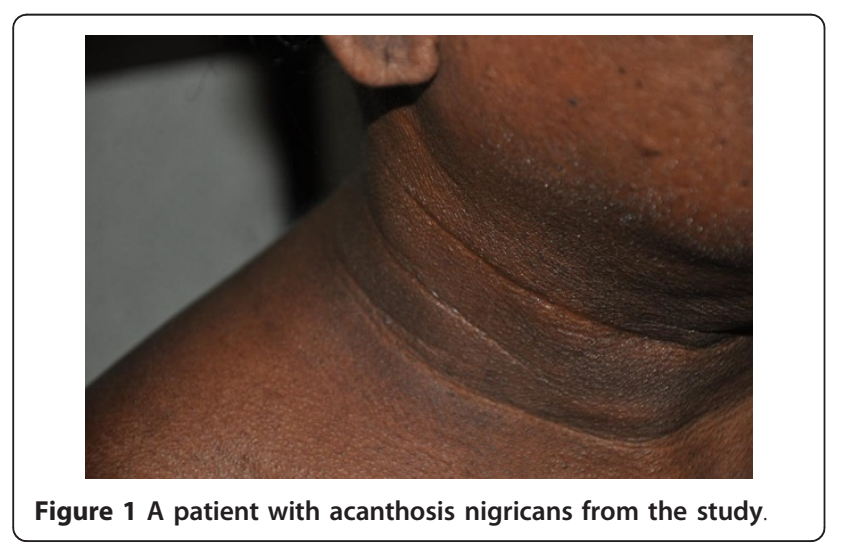

(Mr KDEPN) has given informed written consent for it to be published.

\section{Statistical analysis}

Data were entered in Epi Info 2000 (Centres for Disease Control and Prevention, Atlanta. GA) and logical and random checks were done. Statistical analysis was done using SPSS version 16.0 (SPSS Inc., Chicago, IL). Continuous and categorical data were described using mean and standard deviations. Significance testing was done using the Student T test, Chi squared test and multiple logistic regression. $\mathrm{p}<0.05$ was considered as significant. The sensitivity, specificity, positive predictive value (PPV), and negative predictive value (NPV) of AN to detect metabolic syndrome were calculated.

\section{Results}

3012 subjects participated in the study and 2957 had information on the presence or absence of AN (Table 1, 2). 515 (17.4\%) had AN, and 1025 (34.8\%) had metabolic syndrome diagnosed by revised ATP III criteria (Table 3, 4). Prevalence of type 2 diabetes mellitus was $18.9 \%$ among males and $20.1 \%$ among females giving an overall prevalence of $19.6 \%(\mathrm{n}=584)$. There were 692 females $(67.5 \%)$ with metabolic syndrome $(\mathrm{OR}=2.29 ; 95 \% \mathrm{CI}$ : 1.96-2.69). Age distribution between sexes was similar [males: mean 52.4 years $(\mathrm{SD}=7.9)$ vs. females: mean 52.4 years $(\mathrm{SD}$ 7.8)]. AN was more common among both males [28.2\% vs. $11.0 \%(\mathrm{OR}=3.18$; 95\% CI: 2.34-4.34)]; and females [29.2\% vs. $11.6 \%(\mathrm{OR}=3.15$; $95 \% \mathrm{CI}: 2.43-4.08)\}$ with metabolic syndrome. The sensitivity, specificity, PPV and NPV of AN to detect metabolic syndrome were $28.2 \%, 89.0 \%, 45.9 \%$, and $79.0 \%$ for males, and $29.2 \%, 88.4 \%, 65.6 \%$ and $62.3 \%$ for females, respectively.

\section{Discussion}

The prevalence of AN in this urban adult population from Sri Lanka was a relatively high $17.4 \%$. To our knowledge, this is the first community based prevalence study of AN from the Indian subcontinent. Our results are comparable with prevalence data in American

Table 1 Demographic and anthropometric variables of subjects with and without AN

\begin{tabular}{lccc}
\hline Variable & $\begin{array}{c}\text { Subjects with } \\
\text { AN }\end{array}$ & $\begin{array}{c}\text { Subjects without } \\
\text { AN }\end{array}$ & $\begin{array}{c}\mathbf{p} \\
\text { value }\end{array}$ \\
\hline $\begin{array}{l}\text { Males [Number } \\
(\%)]\end{array}$ & $206(40)$ & $1138(47)$ & 0.006 \\
Age [Mean (SD)] & $50.8(7.6)$ & $52.8(7.8)$ & $<0.001$ \\
BMl [Mean (SD)] & $27.9(4.0)$ & $23.3(3.9)$ & $<0.001$ \\
Waist [Mean (SD)] & $93.9(9.1)$ & $83.9(10.2)$ & $<0.001$ \\
Hip [Mean (SD)] & $97.5(8.3)$ & $89.9(8.0)$ & $<0.001$ \\
WHR & $0.96(0.07)$ & $0.93(0.07)$ & $<0.001$ \\
\hline
\end{tabular}


Table 2 Demographic and anthropometric factors in subjects with and without metabolic syndrome and acanthosis nigricans

\begin{tabular}{|c|c|c|c|c|c|c|}
\hline \multirow[t]{2}{*}{ Variable } & \multicolumn{3}{|c|}{$\begin{array}{l}\text { Acanthosis nigricans (subjects with metabolic syndrome } \\
\qquad n=1025 \text { ) }\end{array}$} & \multicolumn{3}{|c|}{$\begin{array}{l}\text { Acanthosis nigricans (subjects without metabolic syndrome } \\
\qquad n=1924)\end{array}$} \\
\hline & Present & Absent & $p$ value & Present & Absent & $p$ value \\
\hline & $\mathrm{n}=296(28.9)$ & $\mathrm{n}=729$ & & $n=217(11.3)$ & $\mathrm{n}=1707$ & \\
\hline Age & $51.8(7.4)$ & $54.6(7.0)$ & $<0.001$ & $49.4(7.8)$ & $52.0(8.0)$ & $<0.001$ \\
\hline Males & $94(31.8)$ & $239(33.0)$ & 0.71 & $111(51.2)$ & 899 (52.5) & 0.72 \\
\hline$\overline{\mathrm{BMI}}$ & $28.4(4.0)$ & $25.5(3.4)$ & $<0.001$ & $27.2(3.8)$ & $22.4(3.8)$ & $<0.001$ \\
\hline Waist & $95.3(8.5)$ & $90.3(8.6)$ & $<0.001$ & $92.0(9.4)$ & $81.2(9.6)$ & $<0.001$ \\
\hline$\overline{W H R}$ & $0.97(0.07)$ & $0.96(0.07)$ & $<0.001$ & $0.96(0.07)$ & $0.92(0.07)$ & 0.02 \\
\hline
\end{tabular}

Indians, African Americans and Hispanics. As expected, we found that AN was significantly more common in people with metabolic syndrome. We also found that AN had a high specificity and NPV, but a low sensitivity to detect metabolic syndrome. One of the shortcomings in our study was that we did not quantify AN using a standard scale, and only its presence or absence in the neck was noted. However, we feel that if $\mathrm{AN}$ is to be a useful clinical marker in primary care, its detection would be most likely in an exposed area of skin.

Patients with AN are at risk for all components of the metabolic syndrome, such as, obesity, hypertension, elevated triglycerides, low $\mathrm{HDL}$, and impaired glucose tolerance [12,13]. AN is also highly prevalent in certain ethnic groups [5], and in such populations the easy detectability increases its potential to play a bigger role in detecting people at risk of metabolic syndrome. This would be relevant to many developing countries with poor resources, such as those in South Asia, which are battling rapid increases in diabetes, obesity and other components of the metabolic syndrome. Despite this, there are few studies investigating the role of $\mathrm{AN}$ as a clinical marker to detect people who are at risk of

Table 3 Association of Acanthosis Nigricans with revised ATP III criteria for diagnosis of metabolic syndrome in Asians (based on bivariate analysis)

\begin{tabular}{llll}
\hline Criterion & $\begin{array}{l}\text { Odds } \\
\text { Ratio }\end{array}$ & $\begin{array}{l}\mathbf{9 5 \%} \\
\text { Confidence } \\
\text { limits }\end{array}$ & P value \\
\hline $\begin{array}{l}\text { Abdominal obesity } \\
\text { Waist circumference) }\end{array}$ & 5.64 & $4.41-7.22$ & $<0.001$ \\
$\begin{array}{l}\text { Males }>90 \mathrm{~cm} \\
\quad \text { Females }>80 \mathrm{~cm}\end{array}$ & & & \\
\hline $\begin{array}{l}\text { Triglycerides } \geq 150 \mathrm{mg} / \mathrm{dl} \\
\text { High-density lipoprotein cholesterol }\end{array}$ & 1.56 & $1.25-1.94$ & $<0.001$ \\
$\quad \begin{array}{llll}\text { Males }<40 \mathrm{mg} / \mathrm{dl} \\
\quad \text { Females }<50 \mathrm{mg} / \mathrm{dl}\end{array}$ & & & $<0.001$ \\
\hline Blood pressure $\geq 130 / \geq 85 \mathrm{~mm} \mathrm{Hg}$ & 2.04 & $1.66-2.51$ & $<0.001$ \\
\hline \begin{tabular}{l} 
Fasting glucose $>110 \mathrm{mg} / \mathrm{dl}$ \\
\hline
\end{tabular} & 1.85 & $1.53-2.25$ & $<0.001$ \\
\hline
\end{tabular}

having metabolic syndrome. In a recent study in the USA, $49 \%$ of 676 fifth grade children with AN fulfilled criteria for metabolic syndrome [14]. Some states in the USA have encouraged their doctors to look for AN in children in order to detect those at high risk of developing diabetes mellitus [15]. Several recent studies recommend the use of AN as a marker of insulin resistance in American Indian children [16].

Although AN was common in our study population, its low sensitivity does not make it a suitable screening test to detect metabolic syndrome. However, the high specificity and NPV make AN a very useful sign to predict its presence. Primary health care workers and doctors in resource poor settings should be trained to look for and identify AN, and to refer those with the lesion for further investigation and assessment of insulin resistance and metabolic syndrome.

\section{Acknowledgements}

The authors wish to thank S Karagala, NT Wijesinghe for secretarial help with the manuscript.

Table 4 Association of Acanthosis Nigricans with revised ATP III criteria for diagnosis of metabolic syndrome in Asians (based on multiple logistic regression)

\begin{tabular}{|c|c|c|c|c|}
\hline Criterion & $\beta$ & $\begin{array}{l}\text { Odds } \\
\text { Ratio } \\
\text { Exp }(\beta)\end{array}$ & $\begin{array}{l}95 \% \\
\text { Confidence } \\
\text { limits } \\
\end{array}$ & $P$ value \\
\hline $\begin{array}{l}\text { Abdominal obesity } \\
\text { (Waist circumference) } \\
\text { Males }>90 \mathrm{~cm} \\
\text { Females }>80 \mathrm{~cm}\end{array}$ & 1.553 & 4.72 & $3.67-6.07$ & $<0.001$ \\
\hline Triglycerides $\geq 150$ mg/dl & $0.347^{\prime}$ & 1.42 & $1.15-1.75$ & 0.001 \\
\hline $\begin{array}{l}\text { High-density lipoprotein } \\
\text { cholesterol } \\
\text { Males }<40 \mathrm{mg} / \mathrm{dl} \\
\text { Females }<50 \mathrm{mg} / \mathrm{dl}\end{array}$ & 0.274 & 1.32 & $1.05-1.66$ & 0.020 \\
\hline $\begin{array}{l}\text { Blood pressure } \geq 130 \text { / } \\
\geq 85 \mathrm{~mm} \mathrm{Hg}\end{array}$ & 0.394 & 1.48 & $1.19-1.85$ & 0.001 \\
\hline $\begin{array}{l}\text { Fasting glucose > } \\
110 \mathrm{mg} / \mathrm{dl}\end{array}$ & 0.356 & 1.43 & $1.16-1.75$ & 0.001 \\
\hline
\end{tabular}




\section{Author details}

${ }^{1}$ Faculty of Medicine, University of Keleniya, Ragama, Sri Lanka. ${ }^{2}$ International Medical Centre of Japan, Tokyo, Japan.

\section{Authors' contributions}

HJdeS, ARW, NK conceptualized and designed the study. ASD, APdeS, SR, UK, MAN and AK acquired, analyzed and interpreted the data. MAN, ASD and AK drafted the initial version of the manuscript. All authors critically reviewed and revised the manuscript and contributed to the preparation of the final draft. All authors approved the final version of the manuscript.

\section{Competing interests}

The authors declare that they have no competing interests.

Received: 1 September 2010 Accepted: 28 January 2011

Published: 28 January 2011

\section{References}

1. Burke JP, Hale DE, Hazuda HP, Stern MP: A quantitative scale of acanthosis nigricans. Diabetes Care 1999, 22(10):1655-9.

2. Stuart CA, Gilkison CR, Smith MM, Bosma AM, Keenan BS, Nagamani M: Acanthosis nigricans as a risk factor for non-insulin dependent diabetes mellitus. Clin Pediatr (Phila) 1998, 37(2):73-9.

3. Stuart CA, Smith MM, Gilkson CR, Shaheb S, Stahn RM: Acanthosis nigricans among Native Americans: an indicator of high diabetes risk. Am J Public Health 1994, 84:1839-42.

4. Gilkson C, Stuart CA: Assessment of patients with acanthosis nigricans skin lesion for hyperinsulinaemia, insulin resistance and diabetes risk. Nurse Pract 1992, 17:26-44.

5. Stuart CA, Pate CJ, Peters EJ: Prevalence of acanthosis nigricans in an unselected population. Am J Med 1989, 87:269-72.

6. Hud JA, Cohen JB, Wagner JM, Cruz PD: Prevalence and significance of acanthosis. nigricans in an adult obese population. Arch Dermatol 1992, 128:941-4.

7. Kong AS, Williams RL, Smith M, Sussman AL, Skipper B, Andrew C, Rhyne RL: Acanthosis Nigricans and diabetes Risk factors: Prevalence in Young persons seen in South Western US primary care practices. Ann Fam Med 2007, 5:202-208.

8. Yamazaki Ito S, Yoshida H: Acanthosis nigricans is a reliable cutaneous marker of insulin resistence in obese Japanese children. Paeditr Int 2003, 45:701-705.

9. Grandhe NP, Bhansali A, Dogra S, Kumar B: Acanthosis nigricans:relation with type 2 diabetes mellitus, antropometric varables, and body mass in Indians. Post Med J 2005, 81:541-544.

10. Dassanayake AS, Kasturiratne A, Rajindrajith S, Kalubowila U, Chakrawarthi S, De silva AP, Mizoue T, Makaya M, Wickramasinghe AR, de Silva HJ: Prevalence and risk factors for non-alcoholic fatty liver disease among adults in an urban Sri Lankan population. J Gastroenterol Hepatol 2009, 24:1284-1288

11. Fan JG, Saibara T, Chitturi S, Asia-Pacific working party for NAFLD: What are the risk factors for non-alcoholic fatty liver disease in Asia-Pacific. J Gastroenterol Hepatol 2007, 22:794-800.

12. Rave GM: Role of insulin resistance in human disease. Diabetes 1988, 37:1595-607.

13. Third report of the National cholesterol Education Program (NCEP) expert panel on detection, evaluation, and treatment of high blood cholesterol in adults (Adult treatment panel 111) final report. Circulation 2002, 106:3143-421.

14. Murphy E, Minor VE, Neal WA: Metaboilic syndrome in fifth grade children with acanthosis nigricans. World J Paediat 2009, 5:23-30

15. Jones $L H$, Ficca $M$ : Is Acanthosis nigricans a reliable indicator for risk of type 2 diabetes? I Sch N 2007, 23:247-51.

16. Stoddast ML, Blevins KS, Lee ET, Wang W, Blackett PR: Association of Acanthosis Nigricans with Hyperinsulinaemia compared with other selected risk factor for type 2 diabetes in Cherokee Indians. Diabetes care 2002, 25(6):1009-1014.

doi:10.1186/1756-0500-4-25

Cite this article as: Dassanayake et al: Prevalence of Acanthosis Nigricans in an urban population in Sri Lanka and its utility to detect metabolic syndrome. BMC Research Notes 2011 4:25.

\section{Submit your next manuscript to BioMed Central and take full advantage of:}

- Convenient online submission

- Thorough peer review

- No space constraints or color figure charges

- Immediate publication on acceptance

- Inclusion in PubMed, CAS, Scopus and Google Scholar

- Research which is freely available for redistribution

Submit your manuscript at www.biomedcentral.com/submit 